\title{
Article \\ Power Spectral Analysis of Heart Rate Variability In Hypothyroidism
}

\author{
Matia Ahmed ${ }^{1}$, Noorzahan Begum ${ }^{2}$, Sultana Ferdousi ${ }^{3}$,Shelina Begum ${ }^{4}$, Taskina Ali $^{5}$
}

\begin{abstract}
Background: Hypothyroidism is one of the common clinical problems with high incidence in women particularly in older age. It has profound effect on metabolic processes in almost all tissue of the body and heart is particularly sensitive to thyroid hormone action. Power spectral analysis (PSA)is useful to determine the cardiac autonomic regulation by assessing sympathovagal balance. Objectives: To assess the cardiac autonomic nervous activity by power spectral analysis of heart rate variability in patients with hypothyroidism.Method: This cross sectional study was carried out in the Department of Physiology, Banghabandhu Sheikh Mujib Medical University from $1^{\text {st }}$ July 2008 to $30^{\text {th }}$ June 2009 on 60 female patients of 30-50 years with hypothyroidism (group B). For comparison, 30 age sex matched apparently healthy euthyroid subjects (group A) were also studied. Based on treatment, hypothyroid patients were divided into $\mathrm{B}_{1}$ (patients on their $1^{\text {st }}$ day of diagnosis, before starting of treatment) and $\mathrm{B}_{2}$ (patients with medication for 12-18 months). The patients were selected from the Out Patients Department of Endocrinology, BSMMU. Serum TSH and $\mathrm{FT}_{4}$ levels of all subjects were measured by AxSYM system. To perform power spectral analysis of HRV Total Power(TP), Low Frequency(LF),High Frequency(HF),LF norms (nu),HF norms (nu) and LF/HF ratio were assessed by a Polyrite. For statistical analysis of data, Independent Sample t test, One Way ANOVA and Pearson's correlation coefficient test were done as applicable.Results: The mean serum TSH(38.16 vs2.18;2.04) was significantly higher and $\mathrm{FT}_{4}(5.12 \mathrm{vs} 15.13 ; 15.08)$ was significantly lower $(\mathrm{p}<0.001)$ in group $\mathrm{B}_{1}$ than those of group $A$ and $B_{2}$ The mean values of all the spectral parameters of HRV in euthyroid subjects were within normal range. In untreated hypothyroid patients the mean values of TP ( 77.11vs2702.87;2683.73), HF power(56.68 vs 342.02; 437.34) HF nu( 24.79 vs 36.35;34.55) were found significantly ( $\mathrm{p}<0.001)$ lower $\mathrm{LF} / \mathrm{HF}(1.7 \pm 0.3,3.16 \pm .84$ and $1.93 \pm .58)$ and $\mathrm{LF}$ nu(75.32 vs 63.71, and 65.90) were significantly $(\mathrm{p}<0.001)$ higher and in comparison to both euthyroids and treated patients. Conclusion: Alteration in cardiac autonomic nervous activity characterized by reduced vagal modulation and higher sympathetic activity may occur in the hypothyroid patients..
\end{abstract}

Keywords: HRV, LF HF LF/HF Hypothyroidism

J Bangladesh Soc Physiol. 2010 December; 5(2): 53-59 For author affiliations, see end of text.

http://www.banglajol.info/index.php/JBSP

\section{Introduction}

$\Gamma$ he thyroid gland is the largest endocrine gland of our body, produces two major hormones, thyroxin and triiodothyronine. These hormones play vital role in metabolism, profound effect on sensitivity of tissues to catecholamine, stimulates $\mathrm{O}_{2}$ consumption of most of the cells in the body, necessary for normal growth and maturation and therefore affects every organ and organ system. ${ }^{1,2}$

Hypothyroidism is one of the common endocrine disorder in our country. About $3 \%$ of the general population are hypothyroids. The incidence is 
more in women particularly in older age but men are also affected. ${ }^{3}$

Hypothyroidism may be associated with different cardiovascular and metabolic disorders including autonomic nerve function disorders which are evident by the changes in cardiac autonomic nervous activities (CANA). Increased sympathetic and decreased parasympathetic activities are the usual findings in hypothyroids. Increase in sympathetic activity possibly be due to TRH which directly stimulates sympathetic outflow within the CNS. ${ }^{4}$ Dysfunction of ANS may also affect various other organs.

Heart rate variability is the result of intrinsic cardiac automaticity and an indicator of the interaction between cardiac sympathetic and parasympathetic activity ${ }^{5}$.It has been reported that increase in sympathetic and decrease in parasympathetic activity may reduce beat to beat variability $^{6}$.

Power spectral analysis of HRV can demonstrate the definite impairment in cardiac autonomic control, by its ability to detect sympatho-vagal imbalance ${ }^{5,7}$. Power spectral components for HRV analysis includes Total power, VLF power, LF power, HF power, HF norm, LF norm and LF/ HF ratio ${ }^{5}$.

Several studies reported Lower values of total power, HF power and LF power in untreated hypothyroids than those of euthyroids ${ }^{8-11}$.

Again, higher LF norm and lower HF norm in untreated hypothyroid patients in comparison to healthy control was also reported by some investigators 8,9,12. Cacciatori et al. Galetta et al. observed higher LF/HF ratio in untreated hypothyroids than those of euthyroids and also treated patients ${ }^{9-10}$.

Though most of the time they remain unnoticed, it is possible to prevent the development of various complications related to autonomic dysfunction in thyroid disfunction. In our country, heart rate variability by power spectral analysis was investigated in hyperthyroids ${ }^{13}$. In addition, several studies on autonomic nerve function in some clinical condition and health such as diabetes mellitus, aging process, obesity and post-menopausal women were done by conventional method ${ }^{14-17}$ However, no published data is yet available on hypothyroidism by power spectral analysis.

Therefore, the present study was undertaken to assess the autonomic nerve function status in hypothyroid patients by power spectral analysis of HRV. This study may be useful in screening of autonomic nerve function status in hypothyroidism in order to minimize hypothyroid related complications.

\section{Methods}

This cross sectional study was carried out to observe the HRV by time domain method in 60 hypothyroid female patients (group B) with age ranged from 30-50 years in the Department of Physiology, Bangabandhu Sheik Mujib Medical University from $1^{\text {st }}$ July 2008 to $30^{\text {th }}$ June 2009 . For comparison 30 age and sex matched apparently healthy euthyroid subjects ( groupA) were also studied Hypothyroid patients were further subdivided according to treatment received into $B_{1}$, i.e. untreated hypothyroid patients and $B_{2}$ i.e. treated patients achieving euthyroid status. The patients were selected from the Out Patient Department of Endocrinology, BSMMU and the controls were selected from the same area near to hospital by personal contact. All the subjects were free from heart disease, hypertension, diabetes mellitus. chronic renal failure, psychic disorders, and smoking .

After selection, the subject was thoroughly informed about the aim, objectives and detail procedure of the study before examination and collection of blood sample. They were encouraged for voluntary participation and were allowed freedom to withdraw from the study whenever she liked even after participation. If she agreed to enroll to the study, informed written consent was taken from them. For examination the subjects were advised to have their meal by 9:00 pm on previous night, to remain free from any physical or mental stress, not to take any drugs affecting central nervous system and to have a good sleep at night before the examination 


\section{Article}

day. The subject were advised to avoid tea or coffee at breakfast and to attend the Autonomic Nerve Function Test Laboratory

Between 9:00 to 11:00 a.m. on the day of examination. Then the subject was interviewed and detail history regarding personal history, drug history, past medical history was taken to exclude exclusion criteria. Then thorough physical examinations and anthropometric parameters like height, weight, BMI, were taken and the information were recorded in a prefixed questionnaire. Then the subjects were kept under complete bed rest in supine position for 20 minutes in a cool and calm environment. During this period she was advised not to talk, eat or drink and also not to perform physical or any mental activity, even sleep. Then all preparations for recording of the Heart Rate Variability parameters were made by connecting the channels to a transducer for ECG to a computerized polygraph and 5 minutes recording was taken in resting supine position. Data were obtained by software analysis of the power spectral band of the HRV ${ }^{5}$. After the recording is over, $5 \mathrm{ml}$ of venous blood was drawn from the subject.The serum level of thyroid hormone was measured by Microparticle enzyme Immuno Assay(MEIA) method. Data were expressed as mean \pm SD. For statistical analysis, Independent Sample $t$ test and one way ANOVA were used as applicable.

\section{Results}

All the subjects were matched for age and BMI and no statistically significant differences were observed among them. (Figure 1)

The mean serum TSH was significantly higher $(\mathrm{p}<0.001)$ and $\mathrm{FT}_{4}(5.12 \mathrm{vs} 15.13 ; 15.08)$ was significantly lower $(\mathrm{p}<0.001)$ in group $\mathrm{B}_{1}$ than those of group $A$ and $B_{2}$ but no statistically significant differences were observed regarding both $\mathrm{FSH}_{\text {and }} \mathrm{FT}_{4}$ when compared between group $\mathrm{A}$ and $\mathrm{B}_{2}$ (Table I).

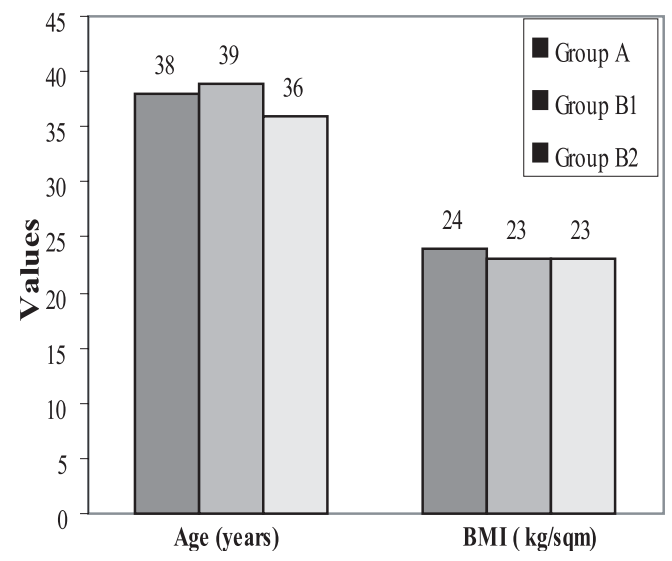

Figigure 1: Age and BMI in different groups $(\mathrm{n}=90)$

Table I: Serum TSH and $\mathrm{FT}_{4}$ levels in different groups ( $\mathrm{n}=90)$

\begin{tabular}{lcc}
\hline Groups & $\mathrm{TSH}(\mathrm{mIU} / \mathrm{L})$ & $\mathrm{FT}_{4}(\mathrm{pmol} / \mathrm{L})$ \\
\hline $\mathrm{A}(\mathrm{n}=30)$ & $2.18 \pm 1.04$ & $15.13 \pm 4.21$ \\
$\mathrm{~B}_{1}(\mathrm{n}=30)$ & $38.16 \pm 30.50$ & $5.12 \pm 1.89$ \\
$\mathrm{~B}_{2}(\mathrm{n}=30)$ & $2.04 \pm 1.01$ & $15.08 \pm 3.95$ \\
\hline
\end{tabular}

Statistical analysis:

\begin{tabular}{ccc}
\hline \multicolumn{2}{c}{ Groups } & \multicolumn{2}{c}{ P values } \\
\hline A vs B $_{1}$ vs B & $0.000^{* * *}$ & $0.000^{* * *}$ \\
A vs B & $0.000^{* * *}$ & $0.000^{* * *}$ \\
A vs B & $0.608^{\text {ns }}$ & $0.964^{\text {ns }}$ \\
B $_{1}$ vs B B $_{2}$ & $0.000^{* * *}$ & $0.000^{* * *}$ \\
\hline
\end{tabular}

Data were expressed as mean \pm SD. ${ }^{* * *}=\mathrm{P}<0.001$. ns $=. \mathrm{P}>0.05$

The mean values of all the spectral parameters of HRV in euthyroid subjects were within normal range. In untreated hypothyroid patients the mean values of TP, HF power, HF nu were found significantly $(\mathrm{p}<0.001)$ lower but $\mathrm{LF} / \mathrm{HF}$ ratio and LF nu were significantly $(\mathrm{p}<0.001)$ higher and in comparison to both euthyroids and treated patients. Again, no statistically significant differences were observed when all these parameters were compared between group $A$ and $\mathrm{B}_{2}$. (Table II \&Table III) 
HIV in Hypothyroidism

Article

Table II: Power Spectral HRV Measures in Different groups(n=90)

\begin{tabular}{llll}
\hline Groups & Total Power $\left(\mathrm{ms}^{2}\right)$ & LF $\%\left(\mathrm{~ms}^{2}\right)$ & HF power $\left(\mathrm{ms}^{2}\right)$ \\
\hline $\mathrm{A}(\mathrm{n}=30)$ & $2702.87 \pm 1297.89$ & $14.65 \pm 10.7$ & $342.02 \pm 362.15$ \\
$\mathrm{~B}_{1}(\mathrm{n}=30)$ & $1177.11 \pm 584.04$ & $17.87 \pm 11.5$ & $56.68 \pm 50.76$ \\
$\mathrm{~B}_{2}(\mathrm{n}=30)$ & $2683.73 \pm 1275.87$ & $14.8 \pm 12.3$ & $437.34 \pm 410.47$ \\
\hline
\end{tabular}

Statistical analysis:

\begin{tabular}{llll}
\hline Groups & & \\
\hline A vs. $B_{1}$ vs. $_{2}{ }^{\mathrm{a}}$ & $0.000^{* * *}$ & $0.825^{\mathrm{ns}}$ & $0.000^{* * *}$ \\
$\mathrm{~A}$ vs. $\mathrm{B}_{1}{ }^{\mathrm{b}}$ & $0.000^{* * *}$ & $0.844^{\mathrm{ns}}$ & $0.000^{* * *}$ \\
$\mathrm{~A}$ vs. $\mathrm{B}_{2}^{\mathrm{b}}$ & $0.954^{\mathrm{ns}}$ & $0.698^{\mathrm{ns}}$ & $0.344^{\mathrm{ns}}$ \\
$\mathrm{B}_{1}$ vs. $_{2}^{\mathrm{b}}$ & $0.000^{* * *}$ & $0.576^{\mathrm{ns}}$ & $0.000^{* * *}$ \\
\hline
\end{tabular}

Data were reported as mean \pm SD.Statistical analysis were done by One way ANOVA ${ }^{\mathrm{a}}$ and Independent sample ' $\mathrm{t}$ ' test ${ }^{\mathrm{b}} . \mathrm{LF}=$ Low frequency, $\mathrm{HF}=$ High frequency, $\mathrm{ms}^{2}=$ squared millisecond.

Table III: Power Spectral HRV Measures in Different groups(n=90)

\begin{tabular}{llll}
\hline Groups & LFnu & HFnu & LF/HF \\
\hline $\mathrm{A}(\mathrm{n}=30)$ & $63.71 \pm 4.07$ & $36.35 \pm 4.12$ & $1.7 \pm 0.3$ \\
$\mathrm{~B}_{1}(\mathrm{n}=30)$ & $75.32 \pm 4.85$ & $24.79 \pm 4.89$ & $3.16 \pm .84$ \\
$\mathrm{~B}_{2}(\mathrm{n}=30)$ & $65.90 \pm 5.23$ & $34.55 \pm 4.67$ & $1.93 \pm .58$ \\
\hline
\end{tabular}

\section{Statistical analysis:}

\begin{tabular}{llll} 
Groups & & \\
\hline A vs. $B_{1}$ vs. $B_{2}{ }^{\mathrm{a}}$ & $0.000^{* * *}$ & $0.000^{* * *}$ & $0.000^{* * *}$ \\
$\mathrm{~A}$ vs. $\mathrm{B}_{1}{ }^{\mathrm{b}}$ & $0.000^{* * *}$ & $0.000^{* * *}$ & $0.000^{* * *}$ \\
$\mathrm{~A}$ vs. $\mathrm{B}_{2}^{\mathrm{b}}$ & $0.161^{\mathrm{ns}}$ & $0.105^{\mathrm{ns}}$ & $0.982^{\mathrm{ns}}$ \\
$\mathrm{B}_{1}$ vs. $\mathrm{B}_{2}^{\mathrm{b}}$ & $0.000^{* * *}$ & $0.000^{* * *}$ & $0.000^{* * *}$ \\
\hline
\end{tabular}

Data were reported as mean. \pm SD. Statistical analysis were done by One way ANOVA ${ }^{\mathrm{a}}$ and Independent sample ' $\mathrm{t}$ ' test ${ }^{\mathrm{b}}$.

LFnorm.= LF power in normalized unit, $[\{L F /$ total power-VLF $\} \times 100]$ HF norm. $=$ HF power in normalized unit, $[\{\mathrm{LF} /$ total power-VLF $\} \times 100] \mathrm{LF} / \mathrm{HF}=$ ratio of low frequency and high frequency.

Group A: Apparently healthy Euthyroids.(control)

Group B : Hypothyroid (study group)

$$
\begin{aligned}
& \mathrm{B}_{1} \text { : Untreated . } \\
& \mathrm{B}_{2} \text { : Treated. }
\end{aligned}
$$

\section{Discussion}

In last decade several investigators had assessed cardiac autonomic activity by power spectral analysis of HRV from the ECG recoding in Hypothyroid patients ${ }^{8,-11,18-20}$.
Different power spectral components of HRV has been used as marker of cardiac autonomic activity. The task force guideline for HRV analysis have demonstrated the interpretation of these parameters to understand the status, behavior 
and the balance between sympathetic and parasympathetic due to their continuous interaction ${ }^{5}$. The total power represents the total variability of R-R interval and is the result of the total cardiac autonomic nervous activities and hormonal activities on heart. Therefore its lower value indicates lower modulation of the cardiac autonomic nervous activities on heart ${ }^{5}$.

Two major component of spectral band, HF power and HF norm reflect the parasympathetic modulation on the heart ${ }^{5}$ and LF power represents the sympathetic activity on the heart; though, some investigators claimed that it is also under some parasympathetic contribution whereas LF norm emphasizes the controlled \& balanced behavior of the sympathetic nervous system ${ }^{5}$.

The cardiac sympathetic and parasympathetic activities are always in interaction. The LF/HF ratio can be considered as a marker of their sympatho vagal balance.

The values of spectral components of HRV in euthyroid subjects in this study were comparable to those reported by the various investigators from different countries . ${ }^{18,21,23,24}$ and also from our country. ${ }^{13-17}$

In this study no significant differences were observed in all these parameters when compared between euthyroid and treated patients with their almost euthyroid status.

In the present study, significantly lower total power in untreated hypothyroid is consistent to the findings of some other studies ${ }^{9-11}$

Again, significantly lower values of HF power and HF norm in untreated hypothyroid indicating their reduced vagal modulation of heart compared to euthyroid and treated hypothyroid patients who obtained euthyroid status. Similar observations were also made by some researchers ${ }^{8-10,12}$.

A conflicting picture regarding LF power and LF norm in hypothyroidism is available from various studies. Some showed an increase, some showed a decrease and some others found no change in LF in hypothyroid compared to euthyroid subjects.

In the present study though higher but statistically not significant value of LF and significantly higher values of LF norm in untreated in hypothyroid is in contrast to those researchers 8,12 , who found significantly lower LF and LF norm in hypothyroids but LF norm is comparable to some studies ${ }^{9}$.

LF/HF ratio was found significantly higher in hypothyroids compared to control and euthyroid treated hypothyroid patients in this study. This finding is consistent to the observations made by some researchers $9,10,25$ but contradicts to other investigator's findings ${ }^{8,12}$.

Findings from research articles analyzing HRV showed that various authors have proposed several mechanisms with physiological background for the observed changes of power spectral components in the deficient state of thyroid hormone in human or in animal model experiment.

It has been suggested that increased sympathetic and decreased vagal modulation might occur in hypothyroidism ${ }^{9,10,26}$. But decreased HR is one of the important feature of hypothyroid which is attributed to desensitization of receptor and also due to cardiac chronotropic response to adrenergic stimulation despite evidence of sympathetic overactivity. It has also been suggested that decreased binding of catecholamine with alpha and Beta receptors in cardiac myocites might be responsible for cardiovascular changes in Hypothyroids ${ }^{10}$. Several investigator suggested that though plasma catecholamines are increased in hypothyroidism but overall depression of adrenergic responses at cardiac and peripheral level indicates desensitization both at the receptor or post receptor site 9,10,21,23,24, 26 .

In this study, higher values of LF power, LF norm are suggestive of presence of sympathetic over 
activity in the hypothyroid patients of the present series. However, decreased values of total power, HF power and HF norm revealed reduced vagal tone in these groups of patients. Moreover, shifting of sympatho vagal balance towards sympathetic predominance in this study is also in favor of sympathetic over activity in hypothyroid patients.

\section{Conclusion}

Alteration in cardiac autonomic nervous activity characterized by reduced vagal modulation and higher sympathetic activity may occur in the hypothyroid patients.

\section{Author affiliations}

1. *Matia Ahmed, Assistant professor, Department of Physiology, Uttara Adhunik Medical College, Uttara.Email: matia.arman@gmail.com

2. Noorzahan Begum, Professor Department of Physiology, Bangabandhu Sheikh Mujib Medical University(BSMMU), Bangladesh, Email: noorzahanbeg@yahoo.com

3. Sultana Ferdousi, Assistant professor, Department of Physiology, Bangabandhu Sheikh Mujib Medical University(BSMMU), Bangladesh, Email:sferdousiratna@gmail.com

4. Shelina Begum. Professor, Chairman, Department of Physiology, Bangabandhu Sheikh Mujib Medical University(BSMMU), Bangladesh.

5. Taskina Ali, Assistant professor, Department of Physiology, Bangabandhu Sheikh Mujib Medical University(BSMMU), Bangladesh, Email:taskinadr@ gmail.com *for correspondence

\section{References}

1. Bucurescu G. Thyroid Disease. [Internet] [cited 2009 Jan 24]. Available from: http:// emedicine.medscape.com/article/1172273overview

2. Ganong WF. Review of Medical Physiology. $22^{\text {nd }}$ ed. USA: Mc Graw-Hill Company; 2005. 332 p.

3. Wikipedia. Hypothyroidism. [internet] [cited 2008 Sept 9] Available from: http://en.wikipedia.org/ wiki/Hypothyroidism

4. Polikar R, Burger AG, Scherrer U, Nicod P. The Thyroid And The Heart. Circulation. 1993; 87:1435-41.
5. Task force of The European Society of Cardiology and The North American Society of Pacing and Electrophysiology. Heart Rate Variability: Standards Of Measurement, Physiological Interpretation And Clinical Use. Euro Heart J. 1996; 17: 354-81.

6. RennieKL,Hemingway H, Kumari M, Brunner E, Malik M and Marmot M.Effects of Moderate and Vigorous Physical Activity on Heart rate Variability in a British Study of Civil Servants. Am J Epidemiol 2006; 158: 135-43.

7. Stys A and Stys T. Current Clinical Applications Of Heart Rate Variability. Clin Cardiol. 1998; 21(10): 719-24.

8. 8. Inukai T, Takanashi K, Kobayashi H, Fujiwara Y, Tayama K, Aso Y, Takemura Y. Power Spectral Analysis Of Variations In Heart Rate In Patients With Hyperthyroidism Or Hypothyroidism. Horm Metab Res. 1998; 30: 531-35.

9. Cacciatori V, Gemma ML, Bellevare F. Power spectral analysis of heart rate in hypothyroidism. Eur J Endocrinol. 2000;143:327-33.

10. Galetta F, Frazoni F, Fallahi P, Rossi M, Carpi.A, Rubello AA, Santoro G. Heart Rate Variability And QT Dispersion In Patients With Subclinical Hypothyroidism. Biomed Pharma therap. 2006; 60: 425-30.

11. Sahin I, Turan N,Kosar F. Evaluation of autonomic activity in patient with subclinical hypothyroidism. J Endocrinol Invest. 2005; 28:209-13.

12. Xing H, Shen $Y$, Chen H, Wang Y,Shen W.Heart Rate Variability And Its Response To Thyroxine Replacement Therapy In Patient With Hypothyroidism. Clin Med J. 2001;114: 906-8.

13. Kabir MR, Begum N, Ferdousi S,Begum S, Ali T.Heart RateVariabilityin Hyperthyroidism. J Bangladesh soc Physiol.2009;49(2):51-7

14. Alam MK,Begum N,Begum S.Parasympathetic Nerve functions in Type 2 Diabetes Mellitus:Relation to glycemic status and duration of Diabetes. J Bangladesh soc Physiol.2008;3:429 .

15. Islam T, Begum N, Begum S, Ferdousi S, Ali T. Evaluation of Parasympathetic Nerve Function Status in Healthy Elderly Subjects. J Bangladesh Soc Physiol. 2008; (3):23-8

16. Akhter S, Begum N, Begum S, Ferdousi S, Ali T. Relationship Between Obesity And Parasympathetic Nerve Function. J Bangladesh Soc Physiol. 2008; (3):50 -4 


\section{Article}

17. Naher LAD, Begum N, Ferdousi S, Begum S, Ali T. Parasympathetic Nerve Function status in Postmenopausal Women. J Bangladesh Soc Physiol. 2009;4(1):45-51.

18. Fagius J, Westermark K, Karlsson A. Baroreflexgoverned Sympathetic outflow to muscle vasculature is increased in hypothyroidism. Clin Endocrinol. 1990; 33(2): 177-185.

19. Gautam S, Tandon OP, Awashi R, Sekhri T, Sircar SS. Correlation of autonomic indices with thyroid status. Indian J Physiol Pharmacol. 2003; 47( 2 ): 164- 170 .

20 Sahin I,Turan N,Kosar F.Evaluation of autonomic activity in patient with subclinical hypothyroidism. J Endocrinol Invest. 2005; 28:209-13.

21. Nielsen HV, Hasselstrom K, Rasmussen U, Mehlsen J, Siersbaek-Nielsen, Friis S,Haunso S, Jensen T. Increased Sympathetic Tone In Forearm Subcutaneous Tissue In Primary Pothyroidism.Clin Physiol.1987;7: 297-302.

22. Foley CM, Mc Allister RM, Hasser EM. Thyroid Status Influences Baroreflex Function And
HIV in Hypothyroidism

Autonomic Contributions To Arterial Pressure And Heart Rate. Am J Physiol Heart Circ Physiol. 2001; 280: H2061-H2068.

23. Manhem P, Bramnert M, Hallengren B, Lecerof H, Werner R. Increased Arterial And Venous Plasma Noradrenalin Levels In Patient With Hypothyroidism During Hypothyroid As Compared To Euthyroid State. J Endocrinol Invest. 1992;15 (10): 763-5.

24. Polikar R, kennedy B, Maisel A, Ziegler M, Smith J, Dittrich H and Nicod P. Decreased Adrenergic Sensitivity In Patients With Hypothyroidism.J am coll cardiol.1990; 15: 94-8.

25. Bhat AN, Kalsotra L, Yograj S. Autonomic Reactivity With Altered Thyroid Status. Jk science. 2007; 9(2): 70-4.

26. Coulombe P, Dussault JH, Letarte J, Simmard SJ. Catecholamine Metabolism In Thyroid Diseases.I. Epinephrine Secretion Rate In Hyperthyroidism And Hypothyroidism. J Clin Endocrinol Metab. 1976; 42: 125-31. 